\title{
Carotid Endoarterectomy (CEA) and Carotid Artery Stenting (CAS): prophylaxis and treatment of stroke
}

\author{
R Russo
}

From de Senectute: Age and Health Forum

Catanzaro, Italy. 5-7 December 2009

\section{Background}

The endoarterectomy (CEA) has always been considered the gold standard for significant carotid stenosis treatment (obstruction of the lumen $\geq 70 \%$ ). The stenting (CAS) techniques have made great steps forward in recent years and it is considered more and more a valid alternative to CEA. The aim of this study is to verify which of the two techniques is most suitable for the treatment of carotid stenosis in the case of primary and secondary prevention of stroke in elderly patients.

\section{Materials and methods}

In this study $\mathrm{Nr} 100$ patients aged $\geq 70$ (F:M 2:1)were enrolled from 2005 to 2008 . Of these, 65 were submitted to CEA and 35 to CAS. 70 patients had had a previous stroke at the anamnesis. The 30 patients with a negative history for strokes presented: carotid stenosis $\geq 70 \%$, hypertension, smoking history, at least one Transient Ischemic Attack (TIA) within 6 months preceding the surgical approach. Even the 70 patients with a history of a stroke showed significant comorbidity, but in these cases surgery was performed within 30 days from the occurrence, Table 1.

In Group A, the choice of technique was influenced by the assessment of the controlateral internal carotid condition: the presence of a stenosis $\geq 60 \%$ directed the

Table 1

\begin{tabular}{lll}
\hline & WITHOUT STROKE (Group A) & PREVIOUS STROKE (Group B) \\
\hline CEA & 5 & 60 \\
CAS & 25 & 10 \\
\hline
\end{tabular}

Chair of General Surgery -Vascular Surgery Training Programme - University Magna Graecia of Catanzaro, Italy choice towards the CAS. In the other cases CEA was performed.

In Group B, CAS was performed in the patients presenting recurrent stenosis after CEA.

Both groups began the antiaggregant therapy.

\section{Results}

The follow up of patients at 12 months after surgery showed for patients in A group only 1 case of stroke at 8 months after surgery in a patient undergoing CEA and no TIA in the rest of the group. For patients in B group, 5 (3 CEA, 2CAS) died of causes unrelated, for the remaining 65: 57 patients undergoing CEA 3 had a new stroke, 3 showed a significant stenosis. In 8 patients undergoing CAS at 12 months there was no complication.

\section{Conclusions}

In the primary prevention of stroke there is no evidence that prefers one technique rather than another. In secondary prophylaxis, although the CEA remains the gold standard technique, the first data collected after 12 months follow-up suggest best results for patients undergoing CAS.

\section{Published: 19 May 2010}

\section{Reference}

1. Bonamigo T, Lucas M, Pivatto F Jr: Results of carotid endarterectomy in octogenarians: A 10-years personal experience. Rev Port Cir Cardiotorac Vasc. 2009, 16(2):81-88

doi:10.1186/1471-2318-10-S1-A74

Cite this article as: Russo: Carotid Endoarterectomy (CEA) and Carotid Artery Stenting (CAS): prophylaxis and treatment of stroke. BMC Geriatrics 2010 10(Suppl 1):A74. 